\title{
THE TECHNOLOGY IMPERATIVE IN EDUCATION
}

\author{
William T. Bonner \\ Abhijit Gopal \\ Faculty of Management \\ Management Information Systems Area \\ University of Calgary \\ Calgary, Alberta \\ Canada
}

\begin{abstract}
The technological imperative can be an insidious master. It can become the central goal of our endeavors rather than just one way through which goals can be reached. This misdirection can have very real and lasting consequences. For this reason, the basis for action in terms of information systems development and implementation must be kept visible to ensure that the broader goals remain the central focus of our efforts.

In the setting in this study, primary education in the Province of Alberta in Canada, everything must change to integrate computer technology. The skills that existing teachers possess are deemed to be inadequate; teachers must be retrained. University education degree curriculums must also be changed. Primary school courses must be altered to integrate computer technology. Physically, schools must be rewired and revamped to accommodate information technology. Provincial spending priorities within education must be changed. A massive social and physical reengineering effort has been launched. In this case, the personal information of the students and direct commercial access to them is being exchanged for computer services.

Whose goals are being served by this requirement of massive change? If it is the goals of educating children, then those who were involved in the process will have had educational goals as their principle focus. There should be stated
\end{abstract}


educational "points" to the exercise and we should be able to discover them. Instead, the study finds that the educational point is never initially articulated and as the process moves along, from vaguely defined goals in one area to the hard requirement of system selection and implementation in another, the educational point question is pushed aside entirely. The technological imperative takes over.

\section{INTRODUCTION}

This case study examines the process through which a specific kind of information technology is selected and implemented in a primary school setting. Avoided here are retroactive justifications and explanations of why specific actions were taken. These justifications, by presenting what occurred as inevitable, ignore the possibility that other alternatives might have at one time existed. The central focus and analysis here is on those who made it happen and their stated justifications for the actions taken.

The study starts with a problematic form sent home by the school for parental signatures. The stance taken in this study is one of being a parent on the "outside," forced into an engagement with those on the "inside." What is discovered is a disturbing pattern of "connected disconnects," as viewed through the theoretical lens of Bruno Latour's actor network theory (ANT). Using this lens, various influential and disparate "experts" emerged at different stages of the process leading to the creation of this form. Certain features from Urlich Beck's work on experts were adopted in order to understand the role of these experts in creating this sense of connected disconnects and of making parents outsiders.

This study first begins with the form itself and follows a parental journey in sense making. This journey highlights the sense of being on the outside of something. The second part of the study employs the theoretical lens of Bruno Latour's actant network perspective to help understand how this situation was created.

\section{THE FORM}

A form arrives from school. The parent is asked to sign the form and return it. The parent looks over the form prior to signing it. One line in particular stands out:

I hereby give permission to issue an account to WhoWhere? Inc. including email, for my child and certify that the infor- 
mation contained on this form is correct. I also consent to the release to WhoWhere? Inc., of the information necessary to establish an account.

The form (Figure 1) was sent to the homes of all children attending schools under the jurisdiction of one of the largest school boards in Canada (hereinafter referred to as the Board). The Board is responsible for approximately 100,000 students from kindergarten through grade 12.

\section{Acceptable Use Policy for Networked Information Resources}

\section{Student}

I understand and will abide by the Acceptable Use Policy for Networked Information Resources. I further understand that any violation of the Policy is unethical and may constitute a criminal offence. Should I commit any violation, my access privileges may be revoked, school disciplinary action may be taken, and appropriate legal action may ensue. I understand that this document will remain in my school file.

Student's Name

Student's Signature

Date:

Student CBE ID \#

Parent or Guardian (If student under the age of 18):

As the parent or guardian, I have read the attached Acceptable Use Policy for Networked Information Resources and I understand that this access is designed for educational purposes and this school has taken reasonable steps to filter inappropriate materials and my son/daughter will be trained in responsible use. However, I also recognize that it is impossible to restrict access to all controversial material or inappropriate material and will not hold the school or Calgary Board of Education responsible for materials acquired on the network. Further, I accept full responsibility for supervision if and when my child's use is not in a school setting. I understand that this document will remain in my child's student record file.

I hereby give permission to issue an account to WhoWhere? Inc. including email, for my child and certify that the information contained on this form is correct. I also consent to the release to WhoWhere? Inc., of the information necessary to establish an account.

Parent/Guardian Name:

Address:

Phone:

Parent or Guardian Signature:

Date: 
No additional information, by way of attachments, was provided with the form. By signing, parents give consent for the release of unidentified personal information - the information necessary - about their children, to a limited liability company, for something called an account, which appears to include email.

For context, we must situate the parent. Refusal to sign means the child is not permitted to see images on computer screens in the classroom that come from the Internet, even if the teacher selected those images. The child will be made to feel different. On the other hand, by signing the form, a parent gives permission to the Board to release unspecified personal information about the child to a limited liability company for purposes unknown.

To add content to the context, we will assume that a parent feels the pressure of the extorted consent and signs the form, but is uncomfortable. The first part of the case study follows a parent's journey to make sense of what has been presented.

\subsection{The Parent and His Journey: Seeking Meaning, Engaging the Text}

The first point of contact is the school that includes grades $\mathrm{K}$ through 6 . Information provided indicates that the Board itself will supply e-mail accounts for the children. No one at the school appears to understand the reference in the form to WhoWhere? Inc. The parent is advised to contact the Board directly. Alone, the parent approaches the Board.

After numerous attempts, contact is made with a senior individual in the technology group at the Board. Information gathered indicates that the cost of providing in-house e-mail service to the 100,000 students would be $\$ 10$ million. A decision was made to outsource the student e-mail function to WhoWhere? Inc. Once the signed form is returned, the Board creates an e-mail account name for the student based on the first and last name. This e-mail account name, the child's first name, last name, date of birth, and gender, are then electronically sent to the limited liability company, in California, which establishes the actual e-mail account. To read or send e-mail, the student goes to this limited liability company's website and logs in.

The child's date of birth and gender are required for advertising purposes. Advertising that appears on the screen is targeted to the age and gender of the child. ${ }^{1}$ Assurances are offered that the information provided is secure and that only the Board and WhoWhere? Inc. has access to the server used.

'No mention was made of advertising in the Acceptable Use Policy for Networked Information Resources that was supposed to accompany the form. 
The parent decides to pursue information about this limited liability company and the assurance of limited access. The parent goes to the WhoWhere? website and is bounced to the Lycos website. Here, DoubleClick banner advertising flashes on the screen with links to free CDs and Pokemon material. Following these links reveals the opportunity to enter contests for merchandise by providing personal information. Somehow associated with WhoWhere? Inc. is an advertising company that is seeking personal information by offering incentives that appeal to children. This will be discussed further shortly. Concerned about the privacy practices of Lycos/WhoWhere?, in light of this entity having personal information about the students, the parent reads the Lycos privacy statement. There another organization appears, TRUSTe.

An attempt to understand the other party that the Board has engaged expands to include Lycos, DoubleClick and TRUSTe. Lycos purchased WhoWhere? Inc., in 1998, for $\$ 158$ million U.S. in Lycos stock and Lycos is now being bought by someone else (Reuters 2000). The limited access assurances offered by the Board to the personal information of the children, appear to be very suspect.

DoubleClick, a banner advertiser, was investigated by the Federal Trade Commission in the U.S., in early 2000, for its plans to track the movements of people on the Web through clickstream data (information about what links people access while online), and link that information to data possessed in the databanks of Abacus Direct Corporation (Clausing 2000a). DoubleClick negotiated a billion-dollar merger with Abacus in 1999 (DoubleClick 1999). The Abacus database contains more than 2 billion consumer catalog transactions. DoubleClick attempted to justify its planned activities, in spite of previously offered assurances that it would not link this data (Brick 1999). In the face of heated public pressure, it withdrew its plans, but only after attempts to "educate" the public about privacy failed (Associated Press 2000; Tedeschi 2000).

Lycos is a member of the TRUSTe program that offers members its seal, for a fee, that is to signify that the site has a privacy policy and that it can be located. This industry-sponsored organization is attempting to encourage computer commerce by assuring people that their privacy will be protected. Yet, "none of the major groups formed to certify and oversee privacy practices [including TRUSTe] have ever pulled a seal of approval from a member Web site" (Clausing 2000b). Their being linked with DoubleClick, through Lycos, weakens TRUSTe's assurances of privacy. DoubleClick considered privacy related issues only after public reaction forced them to retreat from their plans.

\subsection{Summary: Meaning Derived from the Journey}

Two major observations can be made. First, the parent was alone in this journey. Any perception of belonging to a larger group, known as parents, is 
dispelled when a single parent asks questions. From the security of their own home, they are transported alone, through the form, to the school, to the Board, and then off into a corporate maze. Second, in engaging the form, the parent engages a web of others, all foreign to the world of the parent. The school talks about directives from the Board. The Board talks of servers, security, costs, and a single corporation. Tracing this single corporate entity reveals a linkage and web of corporations foreign to the normal world of a parent.

What has this parent accomplished? Trying to understand a single section of a problematic form led to an encounter with a web of organizations that is potentially collecting and using the personal information of captive public school children, all at the initiation of the Board. The Board is asking for consent for this from parents, through their signatures on the form, without telling them anything. How is it that parents are offered so little by way of explanation and at the same time are elevated to legitimate the entire exercise with their signature?

\section{THEORETICAL LENS}

To understand how this occurred, the work of two theorists will be employed. The principal theoretical lens is Bruno Latour's actor network theory (ANT). The specific focus of this lens is on the "How?" question. Concepts from Urlich Beck's Risk Society will be used to help understand how the experts encountered in this case create the feeling of isolation on the part of those that question them.

\subsection{Latour}

ANT views the link between diverse and local centers (network nodes) of a network as being established through interaction. Interaction links local nodes providing the appearance of substance, a network. In action, local nodes of a network invariably interpret and translate calls to action into local terms. Ideas and calls for action do not travel unmolested; they are translated by local actants (Latour 1987, p. 201-202, 1999b, p. 179). The term actant is used to avoid suggesting that only humans can act. An actant is anything that acts or causes action (Latour 1992, p. 256, 1993a, p. 6). This distinction will be discussed shortly.

A network, then, is a series of local nodes, acting locally but giving the appearance of solidity and scale. Scale is created through a series of local efforts that complement each other in such a way as to appear united and large (Latour 1999a, p. 18). This appearance is deceptive as it suggests more sub- 
stance than exists in practice. If local nodes act on something else that is not also local, they are "acting at a distance" (Latour 1987, p. 219, 1988, p. 159).

Central to this perspective is the notion of action defining others. Action is not limited to humans alone. Non-humans forcing others to act or the actions of non-humans themselves, acting, can cause action. A non-human either acts as expected or does something else. Examples of the effects of non-humans might include the unpredictable performance of hardware or software in key situations, such as customer demonstrations, or limiting possible alternative courses of action called for by different strategies. The ability and stability of computer technology are both shaped by actants and shape actants. In interaction, both humans and non-humans define each other.

In order to understand something that is real, one traces the genealogy of the actants that lead to its creation. This move adds context, content, and history, back to the constructed reality by avoiding ahistorical or Whiggish interpretations of events (Butterfield 1950; Latour 1993b, p. 93). Thus, one must immerse oneself, identify the actants and causes of action, and trace the actants back to a time when other possibilities might have existed (Latour 1991, p. 128). Reality is seen as a closed "black box" whose construction must be traced back to its creation where reality was still a question, where it might have been otherwise (Callon 1991, p. 150; Law 1999, p. 7; Star 1991, p. 38).

\subsection{Beck}

According to Beck, we live in a society where the unintended and unconsidered consequences of expert advice leave us exposed to risks: "in the risk society the unknown and unintended consequences come to be a dominant force in history and society" (Beck 1992, p. 22). Isolating their attention to individual cause and effect relationships, experts fail to address or acknowledge the more complex systematic interdependence of events that exist in the "livedin" world. Societal risks and unanticipated consequences emerge from the areas ignored by experts and for which no one is either accountable or responsible. In this "highly differentiated division of labor, there is a general complicity [i.e., experts limiting consideration], and the complicity is matched by a general lack of responsibility" (Beck 1992, pp. 32-33).

Four key aspects of the Risk Society will be highlighted briefly. First, risks or consequences emerge only after action has already been taken (Beck 1992, p. 207). Time separates actions and the manifestation of subsequent side effects. Only later do those affected become aware of the risks resulting from the "considered" opinions of experts.

Second, progress is a form of modern religion. "Progress is a blank page as a political program, to which wholesale agreement is demanded, as if it were the earthly road to heaven" (Beck 1992, p. 214). Progress becomes a "substitute for 
questions, a type of consent in advance for objectives and consequences that remain unknown and unmentioned" (Beck 1992, p. 214). ${ }^{2}$ Experts, speaking in the name of progress, become a driving societal force where the political has limited influence and the sub-political reigns.

Third, these life-altering decisions and actions are being made at the subpolitical level. In the pursuit of progress, the political is irrelevant. By political, Beck means the center, "the normatively valid expectation that the decisions which change society should be concentrated in the institutions of the political system" (Beck 1992, p. 188). Beck argues that experts in the employ of progress operate outside of the parliamentary system altogether. He describes this as the sub-political.

Research laboratories and plant management in the futureoriented industries have become 'revolutionary cells' under the cloak of normality. Here the structures of a new society are being implemented with regard to the ultimate goals of progress in knowledge, outside the parliamentary system, not in opposition to it, but simply ignoring it (Beck 1992, p. 223).

Society shaping decision making has been taken over by the sub-political. "Politics is becoming a publicly financed advertising agency for the sunny sides of a development it does not know, and one that is removed from its active influence" (Beck 1992, p. 224). Dispersed and transient others make societyaltering decisions outside of the political, with the consequence that, "Lacking a place to appear, the decisions that change society become tongue-tied and anonymous" (Beck 1992, p. 187).

Fourth is the paradox of the individual. Individuals are expected to be active participants in the construction of society, yet this role is increasingly subverted by the sub-political. "[The] experts dump their contradictions and conflicts at the feet of the individual and leave him or her with the well intentioned invitation to judge all of this critically on the basis of his or her own notions" (Beck 1992, p. 137). Without their direct participation or understanding, individuals are expected to judge. Yet the society altering decisions are being made anonymously by unseen and unaccountable experts.

\footnotetext{
${ }^{2}$ With respect to computer technology, Postman (1985) echoes these sentiments: "One may also assume that what is called 'computer literacy' does not involve raising questions about the cognitive biases and social effects of the computer, which I would venture, are the most important questions to address about new technologies" (p. 154). Computer technology is seen as progress and need not be burdened with questions or reflections.
} 
The combined effects of the dominance of limited experts, the blank check of progress, the dominance of the sub-political, and the marginalization of the individual creates a disconnect in society. The individual is encouraged to exercise judgement while being relegated to the sidelines.

For what follows, Latour's methodology was employed with the starting point being the form itself. The principal source of information is the public documents each actant produced and documents accessed under the Freedom of Information and Protection of Privacy Act of Alberta. The question changed from the parent's "What does this mean?" to "How was this reality created?" The account that follows is the result of that analysis and is presented chronologically from the origins.

\section{THE ANALYSIS: A DIFFERENT VIEW}

The problem facing the parent was caused by a multiplicity of actants, each linked together but each engaged in different activities. Actants identified include "visionaries," the provincial Ministry of Education, the Board, and the local school. Each will be discussed in turn.

\subsection{The Visionaries}

In 1994, the government created the MLA ${ }^{3}$ Implementation Team on Business Involvement and Technology Integration in Education. A committee was formed to assist the MLA Team, the Technology Integration Advisory Committee (TIAC). These groups are collectively referred to here as the visionaries.

These groups produced the 1995 Technology Integration in Education Discussion Paper (Alberta Education 1995). The MLAs responsible for the report largely credit the TIAC for the perspectives contained in the report (Alberta Education 1995, cover letter). "The committee [TIAC] is comprised of individuals from a diverse range of backgrounds, each with technology expertise" (Alberta Education 1995, p. i).

The theme of computer integration was embodied in the title and throughout the discussion paper. The following introductory comments are indicative of the paper's tone and orientation: "The total storehouse of human knowledge is becoming accessible electronically and the Internet makes it available anywhere, anytime. These are not vague promises of future technologies. We can do it

${ }^{3}$ MLA stands for Member of the Legislative Assembly for the province (in this case, Alberta). 
now" (Alberta Education 1995, p. 1). The idea of something "becoming" and our simultaneously being "able to do it now" is an example of the contradictions contained in this report. These contradictions are exacerbated by the supposition of the need to integrate computer technology without addressing the "Why?" question. "While it is important to know where we are going, it is equally important to know how we are going to get there" (Alberta Education 1995, p. 5). The answer to the "Why" question is presupposed.

We believe that simply putting more computers in the classroom is not the solution. We need to think about technology integration in a broader context: how technology impacts student learning, curriculum, teacher education, learning resources, partnerships, access and planning. Each piece plays a critical role in ensuring that technology is systematically and effectively implemented in producing undeniable benefits to teaching and learning. We need to establish a strong consensus on the direction to take and on how to make it happen (Alberta Education 1995, p. 2).

This action required of everyone amounts to a massive social reengineering project. The pieces must play their role in support of integrating computer technology to produce undeniable benefits to teaching and learning. This is as close as the visionaries come to answering the "Why" question. The undeniable benefits are never articulated. The shift goes immediately to making integration work.

There are consistent themes in this report. The first is that technology is the cause of action. "Technology is changing our world, transforming our work, and Alberta's education system must respond" (Alberta Education 1995, Chair of the Implementation Team, Discussion Paper Press Release). The visionaries promote urgency in response to technology. This is combined with an emphasis on developing workforce skills and adapting to the marketplace, an overriding focus on economic and commercial imperatives (Alberta Education 1995, p. 5). Other themes include computer technology being able to "personalize learning" (Alberta Education 1995, p. 1) and reduce costs (Alberta Education 1995, p. 11). Beyond statements to these effects, no evidence is offered in their support. These statements provide justification for future action without being justified themselves.

The structure of the public discussion paper and the language used precluded the ability of the public to discuss public education and the role of computer technology. Integration was the only option presented. The expected benefits of this were presented in a language of progress and the demands of the information age, without any suggestion of risk or downside potential. The only benefit explicitly claimed was that access to computer technology would become more equitable across rural and urban areas. The case was not made here, nor has it 
been made elsewhere, that students are better or worse off for their position on the accessibility spectrum (Livingstone 1997, p. 102; Moll 1997, p. 54). Only the sunny side of this effort was presented for public discussion.

The visionaries' public discussion paper was followed by a 15 page document entitled Framework for Technology Integration in Education (Alberta Education 1996). The report speaks almost exclusively to an analysis of responses to the questionnaire that was contained in the public discussion paper. The bias of the visionaries toward integration is evident in this analysis. The term integration is absent from the survey questions themselves, but is read into virtually all of the discussions of the questionnaire answers. Two samples are in Table 1. The public is made to appear to support integration despite never being asked about it.

Two other themes emerge in this report: the use of business partnerships and the need to establish performance outcome measures. There was no public discussion of how businesses might support this effort, nor reasons why they would. The claim for support for direct business involvement comes in the discussion of survey respondents' state of agreement to the statement, "Funding for technology should come from contributions from business." The claim is made that roughly $70 \%$ of Albertans agreed or strongly agreed with the statement. Yet, the possibility that business might invoke conditions or attach strings to contributions they might make was not suggested. The most that can reasonably be read into this response is that if business can be persuaded to contribute for computer technology, then Albertans would take it. Any stronger reading of the answer is not justified given the question asked.

The visionaries never appear to have had an educational point. The goal was to integrate computer technology into the classroom. Their document, a call to accommodate computer technology, served as the call to action for others that follow. The next group of experts, the Ministry of Education, took on the establishment of performance measures.

\subsection{The Ministry of Education}

On November 7, 1997, the Ministry started the process of implementing the visionaries' recommendations with a report entitled Learner Outcomes in Information and Communication Technology. This report continued along the same deterministic lines as that of the visionaries. "Technology is causing the process of schooling to undergo phenomenal changes-both in the methods of delivery and in how people actually learn and teach" (Ministry of Education 1997, p. 1). This and other deterministic statements such as, "Technology is more pervasive today than it has ever been in the past," are taken as the cause of action (Ministry Education 1997, p. 1). This ahistorical and deterministic perspective is continued from the work of the visionaries. 
Table 1. Sample Survey Questions and Interpretations

Survey Question: "How important do you believe it is for the future of Alberta students to be
skilled in the use of technology, and to have knowledge and competencies in the use of
information retrieval and processing?"

Interpretation of Answer: "Albertans said that technology integration in education is very important to ensure the success of our students" (Alberta Education 1996, p. 3).

Observation: The word integration, not presented in the question, is read into the answer.

Survey Question: "Please rank the following areas in the priority you think they should be addressed (teacher preparation and support, curriculum development, networking infrastructure, computer hardware and software and clear policy direction)."

Interpretation of Answer: "Albertans have said that providing modern computer technology, appropriate software and access to the information highway for both students and teachers should be among the first priorities in technology integration" (Alberta Education 1996, p. 5).

Note: In this document, the wording of the survey question itself (actual question is above) was rewritten to read: "Albertans were asked to rank the following areas in the priority the elements influencing technology integration should be addressed."

Observation: The word integration, not in the question, was inserted in a revision of the question and the interpretation of the answer.

The focus of these experts was on revising the curriculum and devising performance measures. They produced a series of reports to this effect (Ministry of Education 1998, 1999). Table 2 presents a sample of those measures. They are largely based on counting and the percentage of teachers who use and integrate computer technology in the classroom.

The directive for action for the school jurisdictions clearly comes from the Ministry of Education. "Jurisdictions must respond creatively to [the Ministry of Education's] directions for change, working within their own realities and constraints to implement integration and achieve the required learner outcomes" (Ministry of Education 1999, p. 4.) A consequence of this focus on measuring is the localization of the "Why?" question, which will be discussed in the next section.

The ahistorical view of the visionaries continues in this report. Of 46 references in this report, 41 are to works of the 1990s, three of the 1980s, and two of the 1970s. The visionaries' lack of reflection continues as well. "Technology provides us with the techniques and processes that allow us to think differently and do things differently" (Ministry of Education 1999, p. 10). "Differently" is used as an unproblematic synonym for "better." No comparative story is offered showing how these efforts will improve on the past and assist the attainment of educational goals. This report suggests that there is no 
Table 2. Sample Performance Measure

1. Percentage of teachers who are using and creating learning activities in which the student uses information technology.

2. Percentage of teachers who are using technology as a tool to improve learning (not as an end in itself).

3. Percentage of teachers who are using technology to obtain information and gain access to the learning and teaching resources they need, including resources for professional development.

4. Number of teacher in-service hours on technology-related issues that teachers acquire each year. (Ministry of Education 1998, p. 13)

past and no prior achievements. The focus is solely implementing the vision of the visionaries.

This report contains an appendix outlining some of the experiences of local schools that had started implementing the "learner outcomes." These schools were asked to comment on the challenges they had faced and were anticipating. Common challenges identified include the cost of computer technology, the financial difficulty in keeping pace with technological change, the time constraints caused by limited computer resources, the lack of technological expertise and support, and the problem of keeping up with the children who quickly outpace the available technology. These challenges, experienced by businesses for decades, were not reflected upon in the report.

The work of the visionaries continued and the lack of an educational point was further obscured. The need to accommodate computer technology, as developed by the visionaries, was the single focus of the ministry in the area of their expertise, which was implementation and measurement. The viewpoints of these experts differ, but the visionaries' mission continues.

\subsection{The Local Experts: The School Board}

The Board, a local node on the network that our parent encounters, is charged with meeting the provincial curriculum requirements. These requirements are centered on the notion of computer integration in all areas of study.

The source of required action is reflected in the following message from the Board, located on the WhoWhere? server:

[The Ministry of Education] has mandated that technology become part of the education curriculum by June 2000. In accordance with the new program of studies, it is essential stu- 
dents have skills in e-mail technology. Therefore, the Calgary Board of Education has taken an early lead and decided to move technology into the classroom before the year 2000 (Calgary Board of Education 1998c).

The decision to contract out the service was taken by experts within the Board whose principal concerns were provincial curriculum, computer integration, and cost. Only two documents produced by the Board, the Acceptable Use Policy (AUP) and the Commonly Asked Questions (CAQ), mention WhoWhere? Inc. In these documents, the social reengineering theme is repeated and specific roles are assigned.

Incorporating the Internet into the curriculum will "depend on a coordinated effort, involvement and commitment of the student, the school and the parent." The parent's role in this "involvement" is to "review the Acceptable Use Policy for Networked Information Resources and accepts its terms and conditions" (Calgary Board of Education 1998a). The role assigned to parents by these experts is to review and accept.

WhoWhere? Inc is mentioned once in the AUP document, indicating that a signed consent form "will be deemed to be a consent to give to WhoWhere? Inc. the student's first name, middle name, last name and their password to establish an e-mail account through [the Board]" (Calgary Board of Education 1998a). No mention is made of advertising to children. In the CAQ document, advertising is mentioned, indicating that the Board cannot preview advertisements but can have advertisements removed if they identify some that they do not like (Calgary Board of Education 1998b). No other mention of WhoWhere? Inc. is made, anywhere.

According to the contract the Board has with WhoWhere? Inc., the Board will provide the name, birth year, gender, e-mail address, password, city, province, country and postal code of a student to WhoWhere? Inc. to establish the e-mail account. ${ }^{4}$ In addition to the above information, the contract allows WhoWhere? Inc. to solicit additional information from the children directly, if the Board permits it. It is not clear what the Board's policy is on this. ${ }^{5}$

According to the contract, the Board pays a lump sum to WhoWhere? Inc. and earns $25 \%$ of the net advertising revenue that WhoWhere? Inc. earns.

${ }^{4}$ This contract was accessed under the Freedom of Information and Protection of Privacy Act of Alberta. The AUP document provided a list of personal information the Board was to provide WhoWhere? Inc., while a different list was provided in our parent's initial journey. The contract itself contains a third, more extensive list.

${ }^{5}$ This is currently under investigation. The Board did not answer letters or return telephone calls. A review of the Board's activities has been requested of the Privacy Commissioner of the province. This is currently underway. 
WhoWhere? Inc. has retained the right to sell the banner advertising rights and has sold this right to DoubleClick. In addition, there is the potential for additional shared revenue through e-mail product advertising. The contract requires that acceptance of such e-mail be set as the default position when the e-mail accounts are set up. The Board earns $25 \%$ of the revenue earned from this type of advertising as well.

The Board, with all of this knowledge, shared only what was made available in the consent form sent home for parents to sign.

\section{DISCUSSION}

The analysis reveals a myriad of actants and action, largely those of specialized experts acting locally. The technology experts, the visionaries, determined the required shape of education. Policy and measurement experts at the provincial level put flesh on parts of this vision. The local experts at the Board operationalized it. The school was mandated by the Board to send the form home for parents to sign.

A network of separated experts, focussing on their limited areas of expertise, linked together through local actions taken, constructed this reality. Nothing at the visionary local or at the provincial local dictated that the Board should release students' personal information to a foreign, limited liability company and earn revenue in the process. Each local translated the message received from the preceding node into its own area of expertise and acted upon it.

In engaging the form, the parent is engaging the Board, but also other actants in the background. It is difficult for the parent to see this when engaging a single actant. The calls to action for each node come from elsewhere, from a distance, but the distant calls are translated to local terminology and expertise and appear to be self-contained. Approaching one local for a broader understanding of their actions is virtually impossible, as local experts working with local expertise do not possess a broader understanding. It is not their responsibility, it is not within their expertise, and it is not within their purview. A parent thinking that they should be addressing a single educational system finds, instead, a sequence of separated localities. The false expectation of cohesive action emanating from a single center responsible for the education of their children creates this unexpected encounter with "otherness."

This sort of engagement, implicitly all at once but explicitly one at a time, obscures the creation of reality. Each local node translates the "Why are we doing this?" question. The visionaries answer that they are responding to technology. The province answers that it is responding to the 15 page document created by the visionaries. The Board answers that it is responding to the measurements imposed by the province. The school answers that it is responding to the Board. These fragmented answers translate the entirety into separate 
realities, each of which a parent is left to confront, alone. In Beck's terms, "At the same moment he or she sinks into insignificance, he or she is elevated to the apparent throne of world shaper" (Beck 1992, p. 137). Made insignificant by a fragmented process that excluded them, parents are elevated to the position of sanctioning the outcome.

In attempting to pursue understanding of the form, the decisions leading to its creation appear to be tongue-tied and anonymous. Translations that occurred at the local nodes created a disharmony in attempting to trace a coherent thread of logic through the network to the produced reality. Without its specific history, a constructed reality appears disconnected. Local answers are translated into local language, thereby obscuring the process through which many actants worked to create this reality. This makes it difficult, for someone outside the process, to understand the outcome.

Influencing all of these nodes is a societal faith in the modern myths surrounding computer technology. Computer technology is tied into our vision of progress and being modern. As a consequence, it often receives an unearned free pass from challenges and reflection.

In this case, the human spokespersons for the original experts have dispersed. The room in which the visionaries met is empty. The only trace of their existence is the document they left behind. A non-human is all that remains. At the Board level, the technology experts whose names appear on the contract with WhoWhere? Inc. are no longer with the Board. The consequences of the actions of experts are left to those affected while their spokespersons have faded away.

Understanding the problematic form is made difficult by the work of diverse experts operating locally. Each actant translated their purpose into local language that makes pursuing cohesive meaning across the locals itself problematic. The absence of lasting spokespersons and a pervasive non-reflexive belief in computer technology as the epitome of modernity and progress serve to add legitimacy to a process that has not earned it in its own right.

\section{IMPLICATIONS}

This case illustrates an example where the absence of clear objectives for computer technology leads to the accommodation of the technology itself becoming the goal. The technological imperative slinks in and becomes the focus. It is disturbing to see such little reflection on the part of those involved, throughout the process. This lack of reflection culminated in the form itself.

The upper part of the form appears to be a contract regarding the proper use of information technology. The lower part of the form is expressly a consent form for the release of personal information about the children. They are clearly not the same things but they are bundled as though they were and are treated as 
inseparable by the Board. "This is a legal document and if it is altered in any way it is null and void. There are no exceptions to this rule" (Calgary Board of Education 1998b, p. 2). The experts have spoken and an inviolable rule has been created. We need not accept the pronouncements of the experts but their diversity and anonymity makes them difficult to challenge.

In this regard, it is worth noting the words of Langdon Winner: "Who decided that the changes ahead lie beyond our ideas, voices and participation?" (Winner 1997, p. 187). The decisions taken in this case appear, to an outsider, to be tongue-tied and anonymous. But their implications can and should be brought forward. Winner suggests that "Persons whose professional work gives them insights into the choices that matter must be diligent in expressing their knowledge and judgements to a broad public" (1996, p. 71). The silence, in this instance, on the part of professionals, has been deafening. This need not be and arguably should not have been the case.

An information system was developed, selected, and implemented by information system professionals in the isolation of their organization, the Board. Yet the reach of this system extends far beyond the walls of that organization. We find the impetus for their actions laying in the disconnected focus and efforts of experts that preceded them. Everything must change to accommodate computer technology including the skills of existing teachers, teacher training programs, course curriculums, and the physical schools themselves.

In addition, key assumptions about the shape of technology and the children's role in it have been implicitly made. Delivering the personal information of captive children to "dot com" companies serves to help create a reality that has not yet actually been established, but one that will be shaped in the absence of public discussion. Asking parents to sanction the process with their signatures makes them active accomplices in creating this reality. There appears to be an ethical void with respect to the use of personal information. The actions of DoubleClick are only one example. Their attitude appears to be similar to this senior executive's with respect to gathering and using personal information in the banking sector, "When others define for me what is 'ethical,' I will be ethical. Until then, I will make money" (Smith 1993, p. 112). The Board, regrettably, seems to have adopted a similar stance.

If we, those whose work gives them insight, allow the technological imperative to substitute for clear objectives and goals, what is deemed to be ethical will emerge anonymously from the sub-political, which has a vested interest in actively shaping that outcome.

This case study provides a clear example of the technological imperative becoming the goal and in the process having very real and lasting consequences. In this instance, the insidious absence of an educational point in the entire process led to the creation of this form and instituted a massive social reengineering project that includes delivering captive school age children into the 
arms of marketers, without any apparent pause for reflection. Should outsiders attempt to question the consequence for a point, they are first met by the disconnected rationales of the experts and, if pursued, by a process driven by the ignoble technological imperative.

\section{CONCLUDING COMMENTS}

In investigating this story, Latour's network perspective provided an invaluable tool in aiding in the re-creation of this particular outcome, the form. By focusing on actants and tracing their actions and interactions back in time, we have been led to an empty room where only a document remains and which calls everyone to action. This call to action excludes a clear goal beyond accommodating computer technology. This perspective forces the re-addition of history to outcomes, through the actions of the actants involved.

The use of Beck's experts as actants derived from the writings and citations of the actants involved. At each local level, actants appealed to other authorities and experts as justification and cause for their own actions. The diversity of experts, linked together but using separate frames of reference, lends credence to Latour's insistence that ideas do not travel untrammeled, but are translated along the way. A naïve outsider, in this case a parent, presumes a cohesiveness and unity in logic and effort that never in practice existed.

It is this lack of unity in what the parent encountered and the limited views taken by each group of experts that lead to the form, which to the parent made little sense. Making sense of the entire effort is dumped at the feet of individuals who are left out of the process and, yet, must deal with the outcome.

This study, while specific to the setting, does offer a lens through which such outcomes can possibly be prevented in other organizations where the same kind of phenomenon unfolds, driven by the technological imperative. If Winner's call to advocacy is deemed worthy, this study shows a way in which the isolating rhetoric of experts can be overcome by forcing a broader recognition of their limits and the re-addition of history. If done preemptively, before the black boxes are built, perhaps we can regain control of the right to voice our ideas and actively participate in the construction of reality.

\section{REFERENCES}

Alberta Education. "Framework for Technology Integration in Education," Edmonton: Alberta Government, 1996.

Alberta Education. "Technology Integration in Education Discussion Paper," Edmonton: Alberta Government, 1995. 
Associated Press. "Privacy Advocates Renew Attack on US Internet ad Agency DoubleClick," Calgary Herald, February 15, 2000, p. C7.

Beck, U. Risk Society: Towards a New Modernity, Thousand Oaks, CA: Sage, 1992.

Brick, M. "DoubleClick Raise More Hackles with Privacy Advocates," The New York Times on the Web, 1999.

Butterfield, H. The Whig Interpretation of History, London: B. Bell and Sons, Ltd., 1950.

Calgary Board of Education. "Acceptable Use Policy for Networked Information Resources," Calgary: Calgary Board of Education, 1998a.

Calgary Board of Education. "Commonly Asked Questions About the Acceptable Use Policy for Networked Information Resources (AUP)," Calgary: Calgary Board of Education, 1998b.

Calgary Board of Education. "More About Nomad Mail," Calgary: Calgary board of Education, 1998c (http://www.atts.eduedge.net/nomad/learn.html). This site was last accessed on April 11,2000 . Due to changes as of January 1, 2001 this site is not currently available. The first author can be contacted for paper images of this site, if required.

Callon, M. "Techno-Economic Networks and Irreversibility," A Sociology of Monsters: Essays on Power, Technology and Domination, J. Law (ed.), London: Routledge, 1991, pp. 132155.

Clausing, J. "DoubleClick Moves to Quell Privacy Debate," The New York Times on the Web, February, 15, 2000a, p. B10.

Clausing, J. "Report Rings Alarm Bells About Privacy on the Internet," The New York Times on the Web, February 7, 2000b, p. B10.

DoubleClick. "DoubleClick Inc. and Abacus Direct Corporation to Merge in a \$1 Billion Stock Transaction," DoubleClick Inc., Press Release, New York, 1999.

Latour, B. "On Technical Mediation: The Messenger Series on the Evolution of Civilization," Working Paper Series, Cornell University, Institute of Economic Research, 1993a.

Latour, B. "On Recalling ANT," in Actor Network Theory and After, J. Law and J. Hassard (eds.), Oxford: Blackwell Publishers, 1999a, pp. 14-25.

Latour, B. Pandora's Hope: Essays on the Reality of Science Studies, Cambridge, MA: Harvard University Press, $1999 \mathrm{~b}$.

Latour, B. "The Politics of Explanation: An Alternative," in Knowledge and Reflexivity: New Frontiers in the Sociology of Knowledge, S. Woolgar (ed.), London: Sage Publications, 1988, pp. 155-176

Latour, B. Science in Action: How to Follow Scientists and Engineers Through Society, Cambridge, MA: Harvard University Press, 1987.

Latour, B. "Technology is Society Made Durable," in A Sociology of Monsters: Essays on Power, Technology and Domination, J. Law (ed.), London: Routledge, 1991, pp. 103-131.

Latour, B. "Where Are the Missing Masses? The Sociology of a Few Mundane Artifacts," in Shaping Technology/Building Society: Studies in Sociotechnical Change, W. E. Bijker and J. Law (eds.), Cambridge, MA: MIT Press, 1992, pp. 225-259.

Latour, B. We Have Never Been Modern, Cambridge, MA: Harvard University Press, 1993b.

Law, J. "After ANT: Complexity, Naming and Topology," in Actor Network Theory and After, J. Law and J. Hassard (eds.), Oxford: Blackwell Publishers, 1999, pp. 1-14.

Livingstone, D. W. "Computer Literacy, the 'Knowledge Economy' and Information Control: Micro Myths and Macro Choices," in Tech High: Globalization and the Future of Canadian Education, M. Moll (ed.), Halifax: Fernwood Publishing, 1997, pp. 99-116.

Ministry of Education. "Developing a Three-Year Integration Plan: A Resource," Edmonton: Ministry of Education, June 1998.

Ministry of Education. "Learner Outcomes in Information and Communication Technology," Edmonton: Ministry of Education, November 7, 1997.

Ministry of Education. "Preparing to Implement Learner Outcomes in Technology: Best Practices for Alberta School Jurisdictions," Edmonton: Alberta Ministry of Education, February 1999. 
Moll, M. "Canadian Classrooms on the Information Highway: Making the Connections," in Tech High: Globalization and the Future of Canadian Education, M. Moll (ed.), Halifax: Fernwood Publishing, 1997, pp. 33-64.

Postman, N. Amusing Ourselves to Death: Public Discourse in the Age of Show Business, New York: Penguin Books, 1985.

Reuters. "Lycos Sells for \$12.5B," Calgary Herald, May 17, 2000, p. D17.

Smith, H. J. "Privacy Policies and Practices: Inside the Organizational Maze," Communications of the ACM (36:12), 1993, pp. 105-122.

Star, S. L. "Power, Technology and the Phenomenology of Conventions: On Being Allergic to Onions," in A Sociology of Monsters: Essays on Power, Technology and Domination, J. Law (ed.), London: Routledge, 1991, pp. 26-56.

Tedeschi, B. "DoubleClick's Competitors Relieved, for Now," The New York Times on the Web, March 6, 2000.

Winner, L. "The Handwriting on the Wall: Resisting Technoglobalism's Assault on Education," in Tech High: Globalization and the Future of Canadian Education, M. Moll (ed.), Halifax: Fernwood Publishing, 1997, pp. 167-188.

Winner, L. "Who Will We Be in Cyberspace?" The Information Society (12), 1996, pp. 63-72.

\section{About the Authors}

William (Bill) T. Bonner is a Ph.D. candidate at the University of Calgary in the Faculty of Management. After many years in industry, Bill had the opportunity to teach at Saint Mary's University in Halifax for a number of years. He left to pursue his Ph.D. His immediate focus, his dissertation, seeks to develop an understanding of how, in practice, privacy issues are relegated to the sidelines while "really important" matters are looked after. Bill can be reached by e-mail at bonner@ucalgary.ca.

Abhijit Gopal is an associate professor in the Information Systems area, Faculty of Management, University of Calgary. He has meandered through different academic "religions" and appears finally to have settled in the critical, qualitative domain. His current investigations relate to IT as implicated in the most recent incarnation of globalization as well as how the use of IT in organizational settings might be reinterpreted using alternative theoretical lenses. Abhijit can be reached by e-mail at gopal@mgmt.ucalgary.ca. 